\title{
SEM Model Analysis on the Effect of Antecedents of the University of Nairobi and Jiangsu University's Academic Quality within the Higher Education Institutions
}

\author{
Joseph Muiruri Thige, Hongbo Li, Ssali Max William, Falvian Athiambo \\ School of Management Science and Engineering, Jiangsu University, Zhenjiang, China \\ Email: josephthige@gmail.com, lhb@ujs.edu.cn
}

How to cite this paper: Thige, J. M., Li, H. B., William, S. M., \& Athiambo, F. (2021). SEM Model Analysis on the Effect of Antecedents of the University of Nairobi and Jiangsu University's Academic Quality within the Higher Education Institutions. Creative Education, 12, 1901-1911.

https://doi.org/10.4236/ce.2021.128145

Received: July 7, 2021

Accepted: August 14, 2021

Published: August 17, 2021

Copyright $\odot 2021$ by author(s) and Scientific Research Publishing Inc. This work is licensed under the Creative Commons Attribution International License (CC BY 4.0).

http://creativecommons.org/licenses/by/4.0/

\begin{abstract}
This study is guided specific errand on a dissimilar dataset as in previous study but integrated in way of objective and approach. The study harmonizes the structural estimations concocted in previous studies concerning the impact, relations and associations of and/or amid the five main parameters to and/or amid the academic quality while addressing assortments of micro but different objectives under this errand. Since the previous studies aimed at explicating the comparative significance, directions and correlational characteristics of UJS \& UON's, the current study as partly an extrapolation for this: 1) does robustness diagnostics for the impacts and directions identified towards academic quality in previous study as well as affirming the consistency of the result; 2) innovatively implicates anew objective of the study when the paired homologous structural departments are implicated into the mediation and moderation relation effects, and how the integrative change the academic quality of their respective universities; 3 ) thirdly, the study integrates into new objective when their inter-correlational and analogous comparison is made to identify their temporal similarities and differences while addressing the gap and variance for academic development policy formulation.
\end{abstract}

\section{Keywords}

Higher Education, Academic Antecedents, Variances, Comparative Analogy, Research Design, Causality, Comparability 


\section{Introduction}

\subsection{Review of the Inter-Correlational Expedition and Robustness of Results}

Specifically, what is objectively studied generally as inter-relational of performance, teaching, learner attitude, in this chapter is:

1) The relevance of causality path amid/within the 5-key components of higher academics and its quality, and their impact on academic quality of UON and UJS.

2) The mediation and/or moderation impact on academic quality of the two higher institutions when teaching (performance) variances seemingly intercedes for research (learner attitude) the direct effects on academic quality.

3) The relevance of Inter-correlational postulations amid the UON-UJS departments; research, teaching, and learner attitude towards academic collaboration.

An assortment of research approach is implored for achieving the objectives. The structural equation modelling, correlational models used are integrated and relevantly chosen to fit the data generating process as the results noted are significantly robust and of reliable analysis. The SEM technique is chosen as it best structurally handles primary data generating process and other structural coefficient estimations. Importantly, the SEM best traces the underlying path of causality and or impact to academic quality.

\subsection{Description and Relevance Diagnostics of the New Dataset}

The research design specifically enshrines the approaches such like the description and relevance diagnostics of the new dataset, exploration of relevance of their path of causality, estimation of their structural coefficient, modelling of the mediation/moderation impact and cross-correlation modelling to induce variability and robustness of coefficients.

The most important and useful study results depict that; 1) there exist some significant and underlying causal paths. This implies that the path and/or direction along which teaching, research, performance, learner attitude and internationalization are relevantly significant for the implication that the academic quality is definite and non-virtual with some inter-correlation inducing causalities. Teaching, research, performance, attitude and internationalization significantly cause changes in the academic quality of the respective two universities; 2) Research, teaching and learner attitude are the big three parameters whose changes are key in disorientating the stability of academic quality in both UON and UJS; 3) teaching (performance) best mediates effects of research (learner attitude) for the outfit that objective specific guided research in matters of academics and its structural improvement policy frameworks, and appropriate teaching-learning policies/backdrops, best works to alleviate the quality of education in both universities; 4) Mediation to extent moderates the incoming effect and induces a change of magnitude or of direction or both on outgoing effects so 
that the moderation/mediation effect best demystify that academic quality is best activated when there is integration. Mostly, the mediator is integrated and found mostly positively changing the academic quality; 5) the results of the structural coefficients and estimations postulating varied impacts on the academic quality are robust and consistent under baseline, deviant and paired-integrative modelling, poising their usefulness in policy conclusion.

The above realizations confirm to the achievement of the objective which sought to find out the (inter-)relational association and effects that key parameters of higher academia postulates to the academic quality in the two universities usually perceived as homologous and divergent in structural actuation, and the justification of relevance of the integral scenario for academic collaboration.

\section{Discussion of Results}

The section presents a discussion of the results done in the third and fourth section. Both qualitative and quantitative results have been done based on the demands of the objectives.

The section starts with the regard's qualitative expedition analysis as the concern of the first and second aims. The section assessed the differences between university ranking systems and found that indicators and weights varied greatly creating an undulation of considerations. The "Gap" which is lack of standard indicators explained why international ranking systems rely on publications and survey to gather and simulate data. It also shows why some HEIs do not meet the aggregate for consideration because of their lack of quality academic content and limited or lack of online presence for their academic achievements thus falling short of the threshold for ranking.

\subsection{Result Constrictions}

The section pointed out that ranking systems lacked a central data pool to find data in order to guarantee quality assessment. Limited research was conducted to limit or eliminate such bias. Most significantly, some students had higher expectations of service and quality than was being delivered making it difficult to interpret results based on student satisfaction. While data about the students' experience of the learning environment were important to potential applicants, the comparability of these data across institutions for the purpose of objective ranking is still unclear. Despite the differences in assessment methodologies used to rank universities, there was a level of agreement between ranking systems on which universities are "the best".

Although the meaning of the term quality varied, the ranking systems imposed a standard approach to the matter. As this approach showed, however, exterior ranking systems were not the only way to approach ranking. Indeed, the spread of the World Wide Web provided institutions with an opportunity to improve their own outlook through fair assessment by putting the power of 
ranking in the hands of the consumer and following the standard approach (Trostyanskaya \& Polikhina, 2018; Jarocka, 2015; Muiruri, 2017; Mukhwana et al., 2016; Meredith, 2018; Tosun, 2019; Shahjahan et al., 2020; Trinidad et al., 2021).

As imperfect as they are, ranking satisfies a public demand for transparency and information that institutions and governments had not been able to meet on their own. Moreover, as higher education becomes costlier for individuals and families, the demand for comparative information on universities will increase. As a means of delivering that information, Global HEIs ranking systems are only in their infancy, and will clearly benefit from greater analysis of the assumptions brought forth by the study implicit to their own schemes.

This is particularly the case with respect to international ranking systems, which have a restricted range of possible indicators due to the lack of adequate comparative data. On the other hand, international ranking schemes are taking on a quality assurance role in the growing international student market, this suggests that the global higher education community needs to begin to look at how best to collect and report data on institutions so as to permit thoughtful and responsible inter-institutional comparisons based on transparency and clear accountability to the faith entrusted them by all stakeholders and this finding is mostly reported in literature (Hauptman Komotar, 2019; Johnes, 2018; Li \& Thige, 2017; Nafukho et al., 2019).

\subsection{Ranking Discrepancies and Resemblances}

"Ranking systems are a growing phenomenon in higher education around the globe", the offer is considerably diminished when a strict selection of international ranking of multidisciplinary conducted. Specifically, results obtained in this study are four international university ranking systems selected. The five ranking systems had both convergent and divergent approaches in their production, structure, indicators and weights. This finding has also been reported widely in other studies such as (Altbach et al., 2019; Johnes, 2018; Muñoz-Suárez et al., 2020; Jarocka, 2015; Khamala et al., 2018).

When the researcher tried to cover all the content within the ranking Indicators, weights and diversification in order to find a correlation in the Ranking Systems and come up with a ranking table based on similar indicators, he found wide disparities and therefore chose to list each ranking system independently (Table 1) Ranking alters traditional academic positioning of which combine Higher Education Institutions Development based on the ranking's concept and data. Other controversial aspects of ranking systems are referred to its structure (i.e., numerical or clustering approach).

Every selected ranking listed rank universities according to a numerical approach. The main criticism to this structure was that the differences among closely ranked universities can be due to statistical artifacts rather than true differences. However, solution adopted by benchmarking UJS \& UON against THE 
Table 1. (1-5): Criteria of international academic rankings through indicators and weights comparisons for a five tables infusion.

\begin{tabular}{|c|c|c|c|c|c|c|c|c|c|c|c|}
\hline & Tables & \multicolumn{2}{|l|}{ (1) } & \multicolumn{2}{|l|}{ (2) } & \multicolumn{2}{|l|}{ (3) } & \multicolumn{2}{|l|}{ (4) } & \multicolumn{2}{|l|}{ (5) } \\
\hline \multicolumn{2}{|c|}{ Ranking System } & \multicolumn{2}{|l|}{ ARWU } & \multicolumn{2}{|l|}{ THE } & \multicolumn{2}{|l|}{ QS } & \multicolumn{2}{|c|}{ U.S.News.com } & \multicolumn{2}{|c|}{ WRWU } \\
\hline \multicolumn{2}{|r|}{ Year incepted } & \multicolumn{2}{|l|}{ (2003) } & \multicolumn{2}{|c|}{ (2009) } & \multicolumn{2}{|l|}{ (2009) } & \multicolumn{2}{|l|}{ (2008) } & \multicolumn{2}{|c|}{ (2004) } \\
\hline & Categories & Indicators & Weight & Indicators & Weight & Indicators & Weight & Indicators & Weight & Indicators & Weights \\
\hline \multirow{2}{*}{1} & \multirow{2}{*}{ Research } & Research Output & $20 \%$ & Research & $30 \%$ & $\begin{array}{l}\text { Research } \\
\text { quality }\end{array}$ & $40 \%$ & $\begin{array}{l}\text { Global Research } \\
\text { reputation }\end{array}$ & $12.5 \%$ & presence & $5 \%$ \\
\hline & & - & - & - & - & - & - & $\begin{array}{c}\text { Regional Research } \\
\text { reputation }\end{array}$ & $12.5 \%$ & - & - \\
\hline \multirow{3}{*}{2} & \multirow{3}{*}{ Citations } & - & - & & & - & - & Conferences & $2.5 \%$ & Visibility & $50 \%$ \\
\hline & & Citation impact & $20 \%$ & Citations & $32.5 \%$ & & & $\begin{array}{c}\text { Normalized } \\
\text { Citation impact }\end{array}$ & $10 \%$ & - & - \\
\hline & & Total citations & $20 \%$ & - & - & - & - & Total Citations & $7.50 \%$ & - & - \\
\hline \multirow{4}{*}{3} & \multirow{4}{*}{ Publications } & Publications & $20 \%$ & - & - & - & - & Publications & $10 \%$ & $\begin{array}{c}\text { Transparency/ } \\
\text { openness }\end{array}$ & $10 \%$ \\
\hline & & - & - & - & - & - & - & $\begin{array}{c}\text { Number of } \\
\text { Publications that } \\
\text { are among the } 10 \\
\text { cited journals }\end{array}$ & $12.50 \%$ & - & - \\
\hline & & - & - & - & - & - & - & $\begin{array}{c}\text { Percentage of total } \\
\text { Publications }\end{array}$ & $10 \%$ & - & - \\
\hline & & - & - & - & - & - & - & Books & $2.5 \%$ & - & - \\
\hline \multirow[t]{2}{*}{4} & \multirow[t]{2}{*}{ Performance } & $\begin{array}{l}\text { Quality of } \\
\text { education }\end{array}$ & $10 \%$ & $\begin{array}{l}\text { Industry } \\
\text { income }\end{array}$ & $2.5 \%$ & $\begin{array}{c}\text { Graduate } \\
\text { employability }\end{array}$ & $10 \%$ & $\begin{array}{c}\text { Number of PHDs } \\
\text { awarded }\end{array}$ & $5 \%$ & - & - \\
\hline & & - & - & Teaching & $30 \%$ & $\begin{array}{c}\text { Teaching } \\
\text { quality }\end{array}$ & $40 \%$ & $\begin{array}{c}\text { Number of PHDs } \\
\text { awarded per } \\
\text { academic year }\end{array}$ & $5 \%$ & - & - \\
\hline
\end{tabular}

world Ranking is not free of methodological difficulties, since the apparent distinction between them is vast. A possible solution is to use numerical rankings, but provide the consumer with easily understood information about the extent to which apparent differences in rankings reflect true statistical differences. Further research on this area is needed.

Other aspects subject to debate in specialized ranking literature is the arbitrariness in assigning weights to the various indicators included in the ranking. Data from present study confirm variability on this feature (Table 1(2) \& Table $1(3)$ in the infusion above). Thus, for example, the indicators referred in QS and THE portray many similarities and this might be explained by the initial working relationship between the two which initially worked as one before splitting into the two current systems both in the United Kingdom. The difficulty is how to report results without assigning weights, since the various scores on different indicators cannot then combine into any single score that reflects overall quality 
of a given institution.

The study observed that it is possible to rank universities separately on each indicator, although this option overcomes the assignment of weights to the various measures included in the ranking. It is quite clear that a system that offers so many aspects of university performance, may not be handy for students looking for information to decide on which is the best university. This individualized ranking approach seems more appropriate for the purposes of staff members, institutions and government. Other alternatives suggested by this study are, to survey experts regarding what weights to apply to the different measures. Evaluating and surveying HEIs' quality and reputation are highly useful as well to know their opinions concerning the weighting to assign to indicators for international comparative evaluations. Similar studies with this finding include (Astin \& Solmon, 2012; Fayolle \& Redford, 2014; Han \& Xu, 2019; Jöns \& Hoyler, 2013; Khamala, Makori, \& Njiraine, 2018; Mukhwana et al., 2016; Muñoz-Suárez et al., 2020).

On the flip side of the quantitative expedition, it however had it as the most important expedition outcomes for the third and fourth aims that empirically sought out, generally, the impact and inter-relational effects of key parameters of higher academics to academic quality of UJS and UON using two different sets of data in which the key relevant questions regarding the quality of academics and HEIs academic department have been incarcerated accordingly. Alongside, collected responses have been significantly analyzed with results tabulated in various tables and structural graphics. Results presented range from descriptive analysis, data diagnostics, regressions (ordinal and variance analysis), correlation analysis and a comparative analogy of their variance aside the inter-relations and diagnostics of the robustness.

To be specific, third objective of current study depicts it as geared towards finding out the comparative significance, directions and correlational characteristics amid UJS \& UON's contemporary higher education characteristic variances in their process of academic growth and development as they strive to better their higher education's quality. By the fourth aim, its geared at explicating the influential bearings, interrelations and correlational of key parameters of concern (i.e., research, performance, teaching, attitude and internalization) on academic quality of UON and UJS while using deeply enshrined data generating structural dataset, and models that are best known to capture well primary dataset underlining relations. This exercise is also in a bid to ascertain the relevant and key effects/impacts reported in the previous chapter. The overall empirical errand is an extension of the third objective of the study to generally address the temporal academic variances amid UON and UJS as it explicitly aims to address the academic collaboration amid the two universities.

Largely, departmental developments of universities of Nairobi and Jiangsu are contrastively compared using varied approaches and collection of econometric models innovatively designed to befit the presumably underlying data generating process. The SEM econometric technique has been adopted but with variants at 
each stage variable operationalization for a most robust and consistent effect and/or inter-correlations amid the key parameters and academic quality.

Thus, research approach by the study has been all-inclusive ranging from the descriptive statistics for knowing the variables physical espousement and distribution in the population. Here, two sets of data have been described but all circumnavigating the virtual academic quality parameters of UON and UJS for which have been assembled from the observed parameters using an online questionnaire. Their most relevant measures of distribution and central tendency have been presented which generally postulates that the data set 1 and 2 are normally distributed and as reliability statistic on the other hand portraying acceptance of the null hypothesis for significant Cronbanch alpha weight as in studies of (Mukhwana et al., 2016; Muñoz-Suárez et al., 2020), and depicting that the data is reliable for subsequent analysis. Both the confirmatory test and the path component analysis are key in identifying and explicating whether the underlying variable integration, and or direction of integration is likely not to be spurious. If spurious, then the data may be enshrining an assortment of anomalies for which any further analysis may be inept and irrelevant. However, confirmatory test analysis confirms that there exist some significant and underlying causal paths. This implies that the path and/or direction along which teaching, research, performance, learner attitude and internationalization are relevantly significant for the implication that the academic quality is definite and non-virtual with some inter-correlation inducing causalities as in studies of (Mukhwana et al., 2016; Nafukho et al., 2019; Rybinski, 2020; Saez de Cámara et al., 2021).

For prior comparative realizations depicting to the fact that there could be an existing comparative structural difference amid the UON and UJS. That is, teaching and research seems to be the most key parameters of academic quality while the comparative analogy of mean values for teaching and research for the universities depicting some significant disparities amid the two university's "academics. Since teaching and research seem to be key parameters of academic ranking. Teaching mean value for UON has less weight than for UJS but UONs" research overpowers that of UJS for a prior apparent postulation that the university of Nairobi best excels in research as teaching is best excelled in UJS (Li \& Thige, 2017; Muiruri, 2017).

With the confirmation of normality of the data, and having realized its best fitting from a further deep but structural enshrined analysis of the dataset to identify their underlying correlations and interconnections, and the general influence they have on academic quality. The author indicted the structural equation modelling to suitably explore the objectives of concern while, and succinctly addressing the dynamics of the data for appropriate variance demystification.

Further analysis was based on the demands of the objectives. For instance, the data set 1 which was implicated using ordinal regression, independent T-test, and the Variance analysis was of the am to satisfy the demands of the third objective. The quest for analogous contrasting of the variances of UON and UJS to identify the gap resulted in analyzing the variances and subsequently their beha- 
vior in their correlation matrix. The fourth objective is integrated in checking the impact, effects of the parameter variances on the academic quality of UON and UJS. Largely, since previous objective aimed at finding out the comparative significance, directions and correlational characteristics of UJS \& UON, the objective (4) as partly an extrapolation for (1) robustness diagnostics for the impacts and directions identified towards academic quality in previous chapter as well as affirming the consistency of the result, concerns; (2) innovatively implicates anew objective of the study when the paired homologous structural departments are implicated into the mediation and moderation relation effects, and how the integration changes the academic quality of their respective universities; (3) the objective integrates into some new approach when their inter-correlational and analogous comparison is made to identify their temporal similarities and differences while addressing the gap and variance for academic development policy formulation.

From the above, the confirmatory test analysis, we confirm that there exist some significant and underlying causal paths. This implies that the path and/or direction along which teaching, research, performance, learner attitude and internationalization are relevantly significant for the implication that the academic quality is definite and non-virtual with some inter-correlation inducing causalities.

In the third objective, which was integrative in approach has results and associated analysis rich in variety of findings. In summary, the objective aimed at working out the variances of the two universities (UON and UJS) using rich methodological techniques and approaches relevant to the data demands. A review of its research design entails that; initially, the data is described to determine its physical characteristics, and give its insights of reliability and suitability in modelling. A note from this exercise demonstrated the data to be abnormal in distribution as this provided the hint for selecting the best method of data collection. Relevant methods of variable operationalization took course starting with the ordinal regression, independent T-test and correlation matrix that were important for comparative analysis. An ANNOVA which proceeded the expedition was important in affirming the robustness and reliability of data. Results noted that the variances of UON and UJS are variegated, first, teaching and research are key ingredients of academic quality with internationalization and performance following the lead as learner attitude is more wanting. Research and teaching are the main academic activities Additionally, when compared, teaching weight of UON and UJS all implied that they both apply some analogous kind of teaching models but dissimilar when the case regarded the research-teaching correlation.

Further, based on research relation, it was concluded that the universities employ apparently dissimilar techniques. Revelations of an independent T-test to identify mean equality/variances between UON and UJS parameters of ranking demonstrated that the variances for teaching, internationalization, performance and learner attitude portray differences in their variances. An expedition by the 
ANNOVA technique has probability of the odds in falling at higher level of prediction on academic quality being higher for the teaching parameter in UJS compared to UON for an indication that teaching in UJS is at an advanced level than the teaching in UON. Similar increasing effect is observed with learner attitude for UON but the effect of learner's attitude for UJS is apparently insignificant. Contrast of the effect seems evident when the case regards research that strongly heightens the odds of academic quality increasing for UJS than it's reduced for UJS.

The quantitative specifics, for the generally inter-relational intuitions of performance, teaching, learner attitude had the findings concentrate on relevance of causality path amid/within the 5-key components of higher academics and its quality, and their impact on academic quality of UON, mediation and/or moderation impact on academic quality of the two higher institutions when teaching (performance) variances seemingly intercedes for research (learner attitude) the direct effects on academic quality and the relevance of inter-correlational postulations amid the UON-UJS departments; research, teaching, and learner attitude towards academic collaboration. An assortment of research approach is implored for this aim. Structural equation modelling, correlational models used are integrated and relevantly chosen to fit the data generating process as the results noted are significantly robust and of reliable analysis. The SEM technique is chosen as it best structurally handles primary data generating process and other structural coefficient estimations. Importantly, the SEM best traces the underlying path of causality and or impact to academic quality. Research design specifically enshrines the approaches such like the description and relevance diagnostics of the new dataset, exploration of relevance of their path of causality, estimation of their structural coefficient, modelling of the mediation/moderation impact and cross-correlation modelling to induce variability and robustness of coefficients.

The key results reported that; 1) there underlie certain significant and underlying causal paths. For the notation that direction along which teaching, research, performance, learner attitude and internationalization are significantly important under implied effect that the academic quality is definite and non-virtual with some inter-correlation inducing causalities. Teaching, research, performance, attitude and internationalization significantly cause changes in the academic quality of the respective two universities; 2) Research, teaching and learner attitude are the big three parameters whose changes are key in disorientating the stability of academic quality in both UON and UJS; 3) teaching (performance) best mediates effects of research (learner attitude) for the outfit that objective specific guided research in matters of academics and its structural improvement policy frameworks, and appropriate teaching-learning policies/back-drops, best works to alleviate the quality of education in both universities; 4) Mediation to extent moderates the incoming effect and induces a change of magnitude or of direction or both on outgoing effects so that the moderation/mediation effect best demystify that academic quality is best activated when there is integration. 
Mostly, the mediator is integrated and found mostly positively changing the academic quality; 5) the results of the structural coefficients and estimations postulating varied impacts on the academic quality are robust and consistent under baseline, deviant and paired-integrative modelling, poising their usefulness in policy conclusion.

\section{Acknowledgements}

Joseph Muiruri Thige thanks Professor Li Hongbo, research colleagues Dancun Ominda Hongo, Ssali Max William, Falvian Athiambo and Overseas Educational College, school of management, school of education and the entire fraternity of Jiangsu University for assisting me complete this academic research.

\section{Conflicts of Interest}

The authors declare no conflicts of interest regarding the publication of this paper.

\section{References}

Altbach, P. G., Reisberg, L., \& Rumbley, L. E. (2019). Trends in Global Higher Education: Tracking an Academic Revolution: Brill (pp. 17-19).

Astin, A. W., \& Solmon, L. C. (2012). Are Reputational Ratings Needed to Measure Quality? Change: The Magazine of Higher Learning, 13, 14-19. https://doi.org/10.1080/00091383.1981.9936988

Fayolle, A., \& Redford, D. T. (2014). Handbook on the Entrepreneurial University (pp. 32-38). Edward Elgar Publishing. https://doi.org/10.4337/9781781007020

Han, S., \& Xu, X. (2019). How Far Has the State "Stepped Back": An Exploratory Study of the Changing Governance of Higher Education in China (1978-2018). Higher Education, 78, 931-946. https://doi.org/10.1007/s10734-019-00378-4

Hauptman Komotar, M. (2019). Global University Rankings and Their Impact on the Internationalisation of Higher Education. European Journal of Education, 54, 299-310. https://doi.org/10.1111/ejed.12332

Jarocka, M. (2015). Transparency of University Rankings in the Effective Management of University. Business, Management and Education, 13, 64-75.

https://doi.org/10.3846/bme.2015.260

Johnes, J. (2018). University Rankings: What Do They Really Show? Scientometrics, 115, 585-606. https://doi.org/10.1007/s11192-018-2666-1

Jöns, H., \& Hoyler, M. (2013). Global Geographies of Higher Education: The Perspective of World University Rankings. Geoforum, 46, 45-59. https://doi.org/10.1016/j.geoforum.2012.12.014

Khamala, D. F., Makori, E. O., \& Njiraine, D. M. (2018). Webometrics Ranking and Its Relationship to Quality Education and Research in Academic Institutions in Kenya. Library Philosophy and Practice.

Li, X., \& Thige, J. M. (2017). Benchmarking Jiangsu University to Improve Its Academic Ranking. Online Submission, 8, 178-187.

Meredith, M. (2018). Why Do Universities Compete in the Ratings Game? An Empirical Analysis of the Effects of the US News and World Report College Rankings. Research in Higher Education, 45, 443-461. https://doi.org/10.1023/B:RIHE.0000032324.46716.f4 
Muiruri, T. J. (2017). How to Close the Gap in Global Ranking of Higher Education through Improving the Academic Quality of Jiangsu University (pp. 6-8). Jiangsu University.

Mukhwana, E., Oure, S., Kiptoo, S., Kande, A., Njue, R., Too, J., \& Some, D. (2016). State of University Education in Kenya. Commission for University Education, Discussion Paper, 4(3).

Muñoz-Suárez, M., Guadalajara, N., \& Osca, J. M. (2020). A Comparative Analysis between Global University Rankings and Environmental Sustainability of Universities. Sustainability, 12, 5759. https://doi.org/10.3390/su12145759

Nafukho, F. M., Wekullo, C. S., \& Muyia, M. H. (2019). Examining Research Productivity of Faculty in Selected Leading Public Universities in Kenya. International Journal of Educational Development, 66, 44-51. https://doi.org/10.1016/j.ijedudev.2019.01.005

Rybinski, K. (2020). Are Rankings and Accreditation Related? Examining the Dynamics of Higher Education in Poland. Quality Assurance in Education, 28, 193-204. https://doi.org/10.1108/QAE-03-2020-0032

Saez de Cámara, E., Fernández, I., \& Castillo-Eguskitza, N. (2021). A Holistic Approach to Integrate and Evaluate Sustainable Development in Higher Education. The Case Study of the University of the Basque Country. Sustainability, 13, 392.

https://doi.org/10.3390/su13010392

Shahjahan, R. A., Sonneveldt, E. L., Estera, A. L., \& Bae, S. (2020). Emoscapes and Commercial University Rankers: The Role of Affect in Global Higher Education Policy. Critical Studies in Education, 4, 1-16. https://doi.org/10.1080/17508487.2020.1748078

Tosun, H. (2019). A Performance Assessment Model Recommended for Higher Education System in Turkey and a Case Study. Psychology Research, 9, 420-431. https://doi.org/10.17265/2159-5542/2019.10.003

Trinidad, J. E., Raz, M. D., \& Magsalin, I. M. (2021). "More than Professional Skills:" Student Perspectives on Higher Education's Purpose. Teaching in Higher Education, 4, 1-15. https://doi.org/10.1080/13562517.2021.1891043

Trostyanskaya, I. B., \& Polikhina, N. A. (2018). The Impact of Changes in the World Ranking Methodologies on University Positions. Sotsiologicheskie Issledovaniya, No. 9, 71-79. https://doi.org/10.31857/S013216250001960-9 